\title{
Roma Children Going to Primary School: The Contribution of Interagency Working to Support Inclusive Education
}

\author{
Joana Vale Guerra, Catarina Leitão \\ University of Coimbra, Faculty of Psychology and Educational Sciences
}

\begin{abstract}
Inclusive education can be promoted through partnerships between agencies supporting children and families, such as those in the scope of education, healthcare, social care, and welfare. Partnerships, often referred to as interagency working, were found to determine positive children's educational outcomes, and home-learning environment in previous studies. However, evidence on impact and best practices is still limited. The aim of this paper was to study facilitating factors, and impacts of interagency working for inclusive education. Perspectives of service providers were analysed in regard to a Portuguese project aiming to promote inclusive education and academic progress of children in primary school from a Roma community living in a low-income neighbourhood. Findings indicated that facilitating factors of interagency working for promoting inclusive education included political support, participation of service users in the planning and delivery of interventions, and informal and collaborative working relationships. Positive outcomes were found regarding improved children's school attendance and academic progress, and increased involvement of parents in children's education.
\end{abstract}

Keywords: Choices Programme, education policy, local governance, inclusive education

In Europe, Roma are among the most deprived people, facing limited access to high quality education, labour market barriers, segregation in housing and other areas, and poor health outcomes (European Commission, 2018). The educational attainment of Roma children is lower compared to non-Roma children, and the former tend to be over-represented in special education and segregated schools (European Commission, 2011; European Union Agency for Fundamental Rights [FRA], 2018). According to a survey conducted in eleven European Union member states ${ }^{1}$ (FRA, 2014), on average, $14 \%$ of the Roma children of compulsory school age were not attending formal education, compared to $3 \%$ of the non-Roma children living close by.

The complexity and interdependence of the problems that affect Roma demand an integrated approach, cross-sectoral cooperation, and social investment in local capacities and strategies (European Commission, 2011, 2018). In line with Bronfenbrenner's bio-ecological model (Bronfenbrenner, 1979; Bronfenbrenner \& Ceci, 1994; Bronfenbrenner \& Morris, 2006), the provision of services needs to consider all the relevant environments in which children are embedded to effectively support them (Davidson, Bunting, \& Webb, 2012). Social policy provisions can support efficient use of human capital, while fostering social inclusion of groups that have traditionally been excluded (Morel, Palier, \& Palme, 2016), such as Roma communities.

1 In Bulgaria, the Czech Republic, France, Greece, Hungary, Italy, Poland, Portugal, Romania, Slovakia, and Spain. 


\section{Interagency working and the Portuguese context}

An integrated and holistic approach to support children and their families can be accomplished most effectively through partnerships between agencies, such as those in the scope of education, health, social work, and welfare, among others (Christensen, 2015; Davidson et al., 2012; Statham, 2011). Partnerships and coordination of services have become increasingly recognized as important for the development of effective policies to promote inclusive education (Einbinder et al., 2000; Vargas-Barón, 2016). More than one agency working together in a planned and formal way is often referred to as interagency working (Lloyd, Stead, \& Kendrick, 2001).

\subsection{Interagency working}

Interagency working can include information sharing, and joint assessment of needs, planning and delivery between agencies (Statham, 2011). It may contemplate joint activities involving financial and physical resources, programme development and evaluation, collaborative policies, formal and informal agreements, and voluntary contractual relationships (Dedrick \& Greenbaum, 2011). The organization of services can occur at different levels (e.g. national, regional and local), include various policy domains (European Committee of the Regions, 2009; Frost, 2005; Stubbs, 2005), and diverse types and degrees of integration between agencies (for a review see Barnes et al., 2017).

Interagency working can lead to improved provision of services according to the needs of the users, by reducing duplication and gaps in provision, and consulting users (Atkinson, Jones, \& Lamont, 2007; Statham, 2011). This contributes to avoid repeated requests to families, as frequently found, and lack of services when families do not reach a specific agency (Barnes et al., 2018; Griffin \& Carpenter, 2007). Positive outcomes of interagency working were found regarding children's educational attainment and attendance (Oliver, Mooney, \& Statham, 2010; Statham, 2011), and home-learning environment of families with young children (Melhuish et al., 2008).

According to a literature review by Atkinson and colleagues (2007), effective working relationships depend on clear roles and responsibilities, commitment at all levels of the hierarchy, trust and mutual respect (e.g. skills sharing, equal resource distribution), and understanding between agencies (e.g. joint training and recognition of individual expertise). The authors also identified the relevance of effective communication and information sharing, a joint purpose, strategic planning and organisation, what entails ensuring resources, continuity of staffing, and an adequate time allocation.

A review by Barnes and colleagues (2018) also identified the use of a bottom-up approach as a facilitating factor of interagency working. This approach values the input from the local community and the influence of "street level bureaucrats" (Lipsky, 1980/2010), involves an increased participation of non-state actors, and 
addresses new forms of public-private partnerships (Stubbs, 2005). Other facilitat-

ing factors found in this review were: political support; commitment and shared values about collaborative work between agencies; security of funding; strong leadership and clear governance structure; agreement and commitment at all levels on roles and responsibilities; mutual trust and values (e.g. developed through regular meetings); joint training; attention to data sharing; co-location, which may facilitate communication and a shared vision, but it was not found as essential; positive personal relationships between professionals; and professionals' cultural sensitivity (Barnes et al., 2018).

This brief explanation about interagency working highlights the complexity of the politico-institutional and organizational underpinnings that frames the design of social policies. Facilitating factors and impacts of interagency working can be specific to the context where it occurs. For that reason, the features of the Portuguese context are relevant to frame the present study.

\subsection{The Portuguese context}

A national study on Roma communities (Mendes, Magano, \& Candeias, 2014) identified some heterogeneity in the Portuguese Roma population in terms of lifestyle, social and spatial insertion, and socioeconomically resources. However, the percentage of Roma household members at risk of poverty was 96\% in 2011 (FRA, 2018). In 2013, a National Roma Communities Integration Strategy (2013-2020) was set as the first national plan specifically addressed to Roma communities (High Commission for Immigration and Intercultural Dialogue, 2013). The strategy addressed the need to ensure that all individuals complete compulsory education and have access to further education or professional training.

Data from 2016 (FRA, 2018) showed that the educational attainment of Roma children remained lower compared to non-Roma children in Portugal. The share of children with 4-5 years old participating in early childhood education, and the share of children of compulsory-schooling age participating in education were respectively $42 \%$ and $90 \%$ in the Roma population, compared to $94 \%$ and $99 \%$ in the general population. The share of the population aged 18-24 years not involved in further education or training beyond the lower secondary education was $90 \%$ in the Roma population, compared to $14 \%$ in the general population. The share of Roma children attending segregated education increased from 3\% to 11\% between 2011 and 2016 (Directorate-General for Statistics of Education and Science, 2017; FRA, 2018).

The report from the European Commission (2019) on the implementation of national Roma integration strategies concluded that the coordination of Roma inclusion policy is not yet consolidated in Portugal. The report refers that this is due to lack of information about the strategic guidelines and commitments undertaken by the ministries among the professionals in the areas of intervention, and deceleration on inclusion processes in some municipalities related to the socioeconomic context and recent economic crisis. 
In the national study on Roma communities (Mendes et al., 2014), professionals working in the field of social inclusion reported difficulty in meeting all the requests for support, many of which were beyond institutional resources available or involved other sectors, and acknowledged the possibility of replication of services provided across institutions. The professionals also referred the lack of methodologies for approaching Roma communities and promoting their greater participation in community activities, as well as better educational outcomes for children. In this context, partnerships between agencies are relevant to optimize the existing resources.

In Portugal, interagency working on inclusive education and social support has been created as part of a central government strategy to support the delivery of programmes at the local level. The Choices Programme (Programa Escolhas) is a nationwide programme aiming to promote social inclusion of children and young people (with ages between 6 and 30 years old) from more vulnerable contexts, particularly descendants of migrants and from Roma communities. The programme is developed by a public institute (High Commission for Migration) and includes a large number of projects. Interagency working at the local level is a cornerstone of the projects, what gives an innovative value to this social policy. The local partnerships are established in consortia seeking complementarity, resources coordination, and co-responsibility for initiatives, in order to promote the sustainability of actions. Partners from different levels of action and authority may participate in the consortia, namely government institutions, social partners, entrepreneurs, NGOs, education and scientific sector, representatives of the civil society, and others. This organization reinforces partnership practices, both vertically between local, regional, and national levels, and horizontally between local and civil society organizations.

The projects funded by the Choices Programme are subordinated to a set of principles, namely strategic planning, partnerships, participation, intercultural dialogue, mediation, social innovation, and entrepreneurship. The contractual relation between partners defines roles and responsibilities, in terms of financial, human and material resources. Each project identifies areas requiring intervention and local needs, what reinforces the sharing of a strategic vision and compatible targets among partners. All are equal members in a predetermined organizational structure.

In the current national context, more information is needed about the facilitating factors, and impacts of this new policy implementation involving the delegation of competencies between central and local government to support inclusive education. The importance of attending to this need is reinforced by the inexistence of an independent agency responsible for monitoring interagency working aiming to support young children and their families.

\subsection{The present study}

The goal of the present study was to identify facilitating factors, practices, and impacts of interagency working for inclusive education of Roma children. For this purpose, a case study of a Portuguese project was conducted. The project aimed 
to promote inclusive education and academic progress of children in primary school from a Roma community living in a low-income neighbourhood. The project was funded by the Choices Programme, and it was considered a promising case of interagency working according to criteria specified next. Perspectives of professionals working in public, private and non-profit organizations were collected, since these sectors are playing an increasingly important role in the implementation of social policies in Portugal. Additionally, multi-actor analysis reflects the philosophy of the Choices Programme.

Identifying facilitating factors, practices, and impacts regarding interagency working can contribute to ensure adequate social responses and services to support the needs of children, young people and their families, as well as of the wider community. Researching impacts of interagency working on children and families is a priority, since the information available is scarce (Barnes et al., 2018).

\section{Method}

A project aimed at a large Roma community and funded by the Choices Programme was selected for the present case study.

\subsection{Participants}

In 2017, the project supported 83 children, and 75 parents and other family members. Participants in the focus group and semi-structured interviews of the present study included seven service providers, namely one regional coordinator, one professional of the technical team of Choices Programme, one executive manager, one teacher, one community facilitator and two stakeholders from the private sector. The views of one community facilitator and one activities monitor were also registered through the analysis of dissemination materials of the project.

The project selected was identified as an example of successful interagency working in Portugal (Barnes et al., 2018), based on four criteria. First, the Choices Programme was nationally and internationally recognized as an efficient public policy (e.g. receiving the Juvenile Justice without Borders International Award) and exists for more than 15 years. Second, collaboration was established with a university for evaluation purposes (beyond the internal evaluation within the Choices Programme). Third, the select project was operational for at least two years (it started in 2010), constituting an example of continuity. Fourth, the project used social media regularly to share information with a large audience, and to connect people within and outside the community neighbourhood, providing platforms for civic engagement and action. 
The seven participating service providers were invited to a focus group and semi-structured interviews. The questions focused on: perception of the project in terms of interagency working; details of personal experiences of working with other agencies; overall conclusions and recommendations; mission of the project; philosophy of interagency working; articulation between agencies and levels (public, private and third sector); advantages and impacts; facilitating factors, and challenges regarding the interagency work conducted.

Assessment reports (one internal and two external) and dissemination materials (four videos and two articles in magazines) were also analysed in regard to the relevance attributed to leadership, mission, goals and resources of the project. Legislation on the Choices Programme was analysed with a focus on mission, goals, principles, and responsibilities of each partner involved in the consortium.

\section{Results}

Findings based on the focus group, semi-structured interviews, documents and dissemination materials indicated that all participants, in general, viewed interagency working as positive, contributing to the promotion of social inclusion by developing interventions that took into account the needs of the target users.

\footnotetext{
Working with social exclusion phenomena requires integrated and shared actions between the different actors of the society. (...) Work in partnership has been a relevant factor in promoting social inclusion because local actors can identify the needs that local people feel. (Regional coordinator of the Choices Programme)

We think it is crucial to network and to intervene with other local entities. (Project manager)
}

Some services worked together towards consistent goals, but maintained their institutional independence, while other services worked together in a planned and systematic way, with agreed shared goals, formal decision rules and a continuum of joint action. The project was an example of multi-partner governance because it was developed together with local government, neighbourhood leaders and voluntary organizations, in order to maximize the community empowerment, feelings of neighbourhood identity and belonging.

\subsection{Facilitating factors}

Analyses of the focus group, semi-structured interviews, documents and dissemination materials indicated the relevance of the use of a bottom-up approach as a facilitating factor of interagency working. The project recognized the value of considering all perspectives, including from the users of the services, namely chil- 
dren, young people and their families, in order to provide more appropriate services,

efficiency in delivery, and effective outcomes. Users were asked by the project staff about their views, and participated in the planning and delivery of services to better meet their needs, interests, and expectations.

Our activities pay close attention to the main interests of our children and youth. We have many activities that were proposed by the residents. I think we are very sensitivity to the local context and Roma culture. (Project manager)

To consolidate a bottom-up approach, the project set up a group of volunteers, and established an informal working relationship with local actors of the private sector seeking to participate in the community life. The bottom-up approach involving numerous actors shaped the final output according to the demands, resources and competencies available at the local community.

Other facilitating factors of interagency working found were shared values and trust between partners involved in the project, and a positive organisational climate, with low conflict and high cooperation. All participants suggested that the organizational climate was the primary predictor of positive service outcomes. Participants referred that agencies and organizations were gaining knowledge about each other, and that there was an increasing need for alliances to address the complex issues of our society. However, in general, informality and adaptability tended to characterize the functioning and overall management, and evaluation model of local partners.

Everything is quite easy when we know each other and when we can pick up the phone. (Project manager)

Is quite easy to interact with school because I am going there almost every day. (ICT teacher)

The collaboration with informal partners played an important role because they could participate and invest in activities which brought value to the project goals. For instance, a local corporation financially supported the mission of rewarding 20 children by assigning a gift card based on school attendance and results, adequate behaviour, participation in study activities and in non-formal education activities. When informal partners shared the same values and principles of the project, this cooperation was perceived as good for both sides.

Our company enjoys a lot to support children. On the other hand, it is gratifying to work with a noble institution with a very important mission. (Corporation member) In the scope of social responsibility activities, I consider local corporations contributions a major help to stimulate and create activities for the children we support. (Executive assistant)

The project formal partners developed a relationship based on the principles of good partnership. It was effective because the partners shared a strategic vision, 
32 pursued compatible targets, and were all equal members in a predetermined organizational structure.

In terms of barriers regarding interagency working, findings from the focus group and semi-structured interviews indicated financial uncertainty, and potential reorganisation or ending of the national funding Choices Programme. Additionally, identified barriers included local needs at odds with national priorities, diverse agency policies, procedures and systems, professional stereotyping, lack of explicit commitment to interagency working by stakeholders, and reluctance of some important local actors to engage.

\subsection{Practices and impacts}

The activities delivered in this project focused on academic success and school support throughout the year (for instance, helping children with their homework, and providing lessons on new technologies). Analyses of the focus group, semi-structured interviews and assessment documents indicated improved children's school attendance and academic progress.

The project, installed in the neighbourhood, was able to develop a close relationship with parents, children and families. The systematic school support, with regular activities and focused on empowering personal development, increased parents' interest in their children's academic life. An example is the Wake Up Programme developed by a group of Roma volunteers, who called children in the morning to go to school, going door-to-door, if parents agreed to participate, with the goal of promoting school attendance. Children and families had also access to classes to learn technological skills, music, dance and sports.

\footnotetext{
We work in schools with children, and in the relationships between school and the families from the social neighbourhood, in order to identify teachers' and students' problems and difficulties, and do the link with the families. We also work during their free time, with a range of activities just as music, dance and sports classes. (Project manager)

When residents see local authorities, teachers, "the city" with concerns about safety, issues around children, learning, and health, just as an example, they reinforce their motivations to empower themselves. (Executive assistant)

We want to open both parties' minds and to help the school and the teachers in their relationships with the families, and to encourage our families to study, giving my own example to their families that is possible for us to study, work and evolve as persons, without ceasing to be who we are. (Community facilitator 1)
}

The project also promoted parents' empowerment through the provision of support to develop job skills.

CID@net is open to all the community and we welcome our children's parents for them to develop their abilities in order to get a job. They can also search for job opportunities and improve their technological skills. (Activities monitor) 
Another important feature was the proximity between parents and professionals to solve problems or clarify doubts. As the project manager said, "residents request for help to read documents, and present questions related to health, about children's school, social support, among other issues". The professionals involved in the project often played as brokers between the users of the project and other social services. The permanent participation of Roma users from several generations suggested their preference for the project. One important outcome was the increasing number of children attending project activities over time. "I am very proud of been a volunteer, then a community facilitator and now a monitor" (Community facilitator 1$)$.

In accordance with the Choices Programme, a positive approach was used to promote social inclusion, focusing on the problems, but also on the opportunities, and resources of the communities. At the organizational level, the selected case evolved in order to strengthen the relationship with the residents of the neighbourhood and with the local community. For instance, private corporations prevailed in its financial support.

The project aimed to promote the conditions necessary for children and young people to maintain and develop their cultural heritage, using their own resources, together with the promotion of school attendance and academic progress. In the scope of the project, young people participated in the production of videos aiming to reduce stereotypes associated with Roma communities, which were then disseminated on the social media of the project. Young people also conducted sessions presenting Roma history and cultural heritage, and children and young people were involved in artistic events, presenting Romani dances and songs. These activities also had the goal of enhancing the relationships between Roma and non-Roma persons. The project organized youth assemblies to potentiate the active participation of young people in processes of decision-making concerning the planning and implementation of activities. A constant focus of the project was on children's and young people's empowerment.

I really think that raising their self-esteem is very important, because they sometimes feel ashamed and are not aware of their multiple abilities that go way beyond working in fairs. Going to school is very important. I also run an animation activity during break time whose goal is to improve the relationship between Roma and non-Roma persons. (Community facilitator 2 )

\section{Discussion}

The present case study was focused on a Portuguese project funded by a national public policy aiming to promote school integration of Roma children in a low-income neighbourhood. The project built on the theory drawn from the interagency working as a valuable instrument to overcome weaknesses of the national policy to support Roma children and families. Local government, neighbourhood leaders, volunteers, 
34 private and public organizations were brought together. The results of the study supported that interagency working with multi-actors can constitute a strategic plan to support Roma children and families by promoting inclusive education. As reported in the national study on Roma communities (Mendes et al., 2014), multidisciplinary teams were perceived as essential to work on the promotion of social inclusion.

Findings pointed out the advantages of a bottom-up approach in guaranteeing adequate social responses and services to the needs of children, young people and their families. Despite the advantages associated with this bottom-up approach, some concerns arise when the government transfers to the private sector some roles or services that usually were central State-directed (Donahue, 2006; Verma, 2016). That is why there are benefits to discuss the Portuguese example, considering that it tried to bridge the gap between top-down and bottom-up approaches by incorporating the insights of both perspectives. In this context, political support has been a critical facilitator to provide services with adequate conditions and funding.

Local government agencies have historically functioned as institutions using vertical lines of communication, top-down decision making, differentiation of tasks, hierarchical supervision, and formal rules and regulation. As such, it is common for professionals and administrators to be predisposed to a "chain of command" rather than a shared way of thinking and doing. Professionals and organizations often are highly motivated to form partnerships, but flounder because of the structure, confusion about roles, or expectations for outcomes.

The shifting configuration of actors at the local level gaining significant power can contribute to ensure the exercise of democracy and citizenship. In this scenario, the participation of Roma in the design of initiatives that aim to support them can contribute to their empowering, use of own resources, and to successful policies implementation (European Commission, 2018; FRA, 2018). Area-based partnerships provide a mechanism for local organizations to work together and adapt their policies to better reflect the needs of people at the local level (OECD, 2015).

The organisational climate and the establishing of informal working relationships were also found in the present study as important facilitating factors when developing interagency working. In the national study on Roma communities (Mendes et al., 2014), factors such as adequate professional training, support or patronage to guarantee a certain continuity of time, and monitoring of the projects were also identified. However, according to the European Commission (2019) report on Roma integration strategies, in Portugal the number of measures with funding allocated was below the average of the Member States. According to the same report, one of the key recommendations for the country is that ministries should focus on the training and qualification of their professionals and other key players in fighting discrimination in partnership with civil society organizations (Roma associations and other associations working directly in this field). Another recommendation is the need for municipalities to assume a key role by engaging in local needs assessment, planning and implementation. 
Concerning the practices implemented in the scope of the project under study, these had a strong focus on promoting positive attitudes in regard to school, supporting children to develop study and learning practices, providing extra-curricular activities, and reinforcing school-families partnerships. Community facilitators had also an important role to establish links between Roma and non-Roma communities, and, more particularly, between children, families, and schools. According to the national study on Roma communities, organizations and services should also work with the non-Roma community to integrate the Roma and non-Roma persons in different activities and projects (Mendes et al., 2014).

Findings suggested that the project had positive impacts on the Roma families and community. The community was very collaborative with the project in order to motivate their children to academic achievement, learning of technological skills and occupation of leisure times with music, dance and sports. Children's school attendance and academic performance were also reported as higher.

The follow-up strategies to support Roma children and their families in the community reduced school dropout to zero and improved school performance. Parental understanding about the benefits of school attendance, preparing their children for the unpredictability of the future, and above all securing job opportunities and future skills requirements, contributed to this achievement. According to the Ad Hoc Committee of Experts on Roma and Traveller Issues (Council of Europe, 2018), 65\% of children entering primary school today will ultimately end up working in completely new job types that do not yet exist. In Portugal, the Roma community is also tackling economic restraints due to the consumerism profile of the modern societies that undermined the traditional economic activities. Parents are facing the idea that ignoring the school compulsory education is to compromise their children's future.

Various practices implemented in the project followed the recommendations to improve Roma persons' life provided by the national study on Roma communities (Mendes et al., 2014). The project aimed to develop a more systematic and structured networking with Roma children and families, and a broader and more effective dissemination of their references and cultural repertoire to institutions and the population in general. The project sought to combat stereotypes found in Portugal, such as disinterest by Roma communities in regard to education. According to the same national study, organizations and services should decentralize interventions to involve other populations, as well as the wider geographical environment, and not overly focus on Roma and residential spaces that promote Roma isolation (Mendes et al., 2014).

Local governance is crucial for the effective implementation of strategic action plans to improve the enrolment of Roma children in compulsory schooling. At the local level co-operation is needed between key stakeholders: schools and Roma school mediators, the local authorities responsible for education, multi-disciplinary teams and families.

The partnerships between services working for and with children and families, due to their multi-actor and multi-form structures, were observed in many cases to 
36 lead to indeterminate outcomes (Verma, 2016). However, the evidence collected in this case study can contribute to reinforce information to policymakers and professionals about the best strategies to ensure inclusive education.

\section{Acknowledgements}

The authors acknowledge funding from the European Union's Horizon 2020 research and innovation program under grant agreement No. 727069 (ISOTIS).

\section{References}

Atkinson, M., Jones, M., \& Lamont, E. (2007). Multi-agency working and its implications for practice: a review of the literature. Reading: Centre for British Teachers.

Barnes, J., Crociani, S., Daniel, S., et al. (2018). Comprehensive review of the literature on inter-agency working with young children, incorporating findings from case studies of good practice in inter-agency working with young children and their families within Europe (ISOTIS Report). Retrieved from http://www.isotis.org/resources/publications /isotis-publications

Barnes, J., Melhuish, E., Guerra, J. C., Karwowska-Struczyk, M., Petrogiannis, K., Wysłowska, O., \& Zachrisson H. D. (2017). Inter-agency coordination of services for children and families - Initial Literature Review (ISOTIS Report). Retrieved from http://www. isotis .org/resources/publications/isotis-publications

Bronfenbrenner, U. (1979). The ecology of human development. Cambridge, MA: Harvard University Press.

Bronfenbrenner, U., \& Ceci, S. J. (1994). Nature-nuture reconceptualized in developmental perspective: A bioecological model. Psychological Review, 101(4), 568-586.

Bronfenbrenner, U., \& Morris, P. A. (2006). The bioecological model of human development. In R. M. Lerner (Ed.), Handbook of child development (6th ed., Vol. 1, pp. 793-828). Hoboken, NJ: John Wiley \& Sons.

Christensen, T. (2015, October). Integrated governance: How? Where? For what? Paper presented at the conference Governação integrada: a experiência internacional e desafios para Portugal, Lisboa. Retrieved from http://www.forumgovernacaointegrada.pt

Council of Europe. (2018). Enhancing the effective realization of Roma children's compulsory school education and added value of ensuring access to vocational education for Roma youth. Strasbourg. Retrieved from https://rm.coe.int/cahrom-2018-12-en-final-thematic -report-on-roma-children-s-compulsory-/16808fef22

Davidson, G., Bunting, L., \& Webb, M. L. (2012). Families experiencing multiple adversities: A review of the international literature. Belfast: Barnardo's Northern Ireland.

Dedrick, R. F., \& Greenbaum, P. E. (2011). Multilevel confirmatory factor analysis of a scale measuring interagency collaboration of children's mental health agencies. Journal of Emotional and Behavioral Disorders, 19(1), 27-40.

Directorate-General for Statistics of Education and Science. (2017). School profile of the Roma community 2016/17. Retrieved from http://www.dgeec.mec.pt/np4/906.html

Donahue, J. D. (2006). Public-private collaboration. In M. Moran, M. Rein, \& R. E. Goodin (Eds.), The Oxford Handbook of Public Policy (pp. 496-525). Oxford: Oxford University Press.

Einbinder, S. D., Robertson, P. J., Garcia, A., Vuckovic, G., \& Patti, R. J. (2000). Interorganizational collaboration in social service organizations: A study of the prerequisites to success. Journal of Children and Poverty, 6(2), 119-140. 
European Commission (2011). Communication from the Commission to the European Parliament, the Council, the European Economic and Social Committee and the Committee of the Regions - An EU framework for national Roma integration strategies up to 2020 [Communication]. Retrieved from https://eur-lex.europa.eu/legal-content/EN/TXT/HTML /?uri=CELEX:52011DC0173\&from=EN

European Commission (2018). Communication from the Commission to the European Parliament and the Council Report on the evaluation of the EU Framework for national Roma integration strategies up to 2020 [Communication]. Retrieved from https: / / eur-lex.europa .eu/legal-content/EN/TXT/?uri=CELEX\%3A52018DC0785

European Commission (2019). Communication from the Commission to the European Parliament and the Council. Report on the implementation of national Roma integration strategies - 2019. Brussels: European Commission.

European Committee of the Regions (2009). The Committee of the Regions' White Paper on multilevel governance. Retrieved from https://publications.europa.eu/en/publication-detail/ - /publication/3cba79fd-2fcd-4fc4-94b9-677bbc53916b/language-en

European Union Agency for Fundamental Rights (2014). Education: the situation of Roma in 11 EU member states. Roma survey - Data in focus [Report]. Retrieved from http://fra .europa.eu/en/publication/2014/education-situationroma-11-eu-member-states

European Union Agency for Fundamental Rights (2018). A persisting concern: Anti-Gypsyism as a barrier to Roma inclusion [Report]. Retrieved from https://fra.europa.eu/en /publication/2018/roma-inclusion

Frost, N. (2005). Professionalism, partnership and joined up thinking: a research review of frontline working with children and families. Dartington: Research in Practice.

Gajda, R. (2004). Utilizing collaboration theory to evaluate strategic alliances. American Journal of Evaluation, 25(1), 65-77.

Griffin, M., \& Carpenter, J. (2007). Local programmes and social services: lessons in partnerships. In J. Schneider et al. (Eds.), Supporting children and families. Lessons from sure start for evidence-based practice in health, social care and education (pp. 111-120). London: Jessica Kingsley Publishers.

High Commission for Immigration and Intercultural Dialogue. (2013). National Roma communities integration strategy 2013-2020. Retrieved from https://www.acm.gov.pt/-/estrategia -nacional-para-as-comunidades-ciganas-enicc-concig

Lipsky, M. (2010). Street-level bureaucracy: Dilemmas of the individual in public services. 30 th anniversary expanded edition. New York: Russel Sage Foundation (Original work published 1980).

Lloyd, G., Stead, J., \& Kendrick, A. (2001). Inter-agency working to prevent school exclusion [Report]. Retrieved from https://www.jrf.org.uk/report/inter-agency-working-prevent -school-exclusion

Melhuish, E., Belsky, J., Leyland, A. H., Barnes, J., \& NESS Research Team (2008). Effects of fully-established Sure Start local programs on 3-year-old children and their families living in England: a quasi-experimental observational study. Lancet, 372, 1641-1647.

Mendes, M., Magano, O., \& Candeias, P. (2014). Estudo nacional sobre as comunidades ciganas. Lisboa: Alto Comissariado para as Migrações.

Morel, N., Palier, B., \& Palme, J. (2016). Towards a social investment welfare state? Ideas, policies and challenges. Bristol \& Chicago: Policy Press.

Organisation for Economic Co-operation and Development (2015). Development co-operation report 2015: Making partnerships effective coalitions for action. Paris: author. doi: 10.1787/dcr-2015-en

Oliver, C., Mooney, A., \& Statham, J. (2010). Integrated working: a review of the evidence. Leeds: Children's Workforce Development Council.

Presidência do Conselho de Ministros (2015). Despacho normativo n. 0 19-A/2015 [Normative order, no. 19-A/2015] [Legislation]. Retrieved from https://www.portugal2020.pt. 
38 Presidência do Conselho de Ministros (2018). Resolução do Conselho de Ministros n. ${ }^{0}$ 151/2018 [Resolution of the Council of Ministers no. 151/2018] [Legislation]. Retrieved from https: / / dre.pt/web/guest/home/-/dre/117047302/details/maximized

Rözer, J., \& Werfhorst, H. van de (2017). Inequalities in educational opportunities by socioeconomic and migration background: A comparative assessment across European societies. Retrieved from http://www.isotis.org/resources/publications/isotis-publications

Statham, J. (2011). Working together for children. A review of international evidence on interagency working, to inform development of Children's Services Committees in Ireland. Dublin: Department of Child and Youth Affairs, Government Publications.

Stubbs, P. (2005). Stretching concepts too far? Multi-level governance, policy transfer and the politics of scale. Southeast European Politics, VI(2), 66-87.

Vargas-Barón, E. (2016). Policy planning for early childhood care and education: 2000-2014. Prospects, 46(1), 15-38.

Verma, M. (2016). Role of the state in partnerships with the private sector. Journal of Development of Policy and Practice, 1(1), 53-70.

Dr. Joana Vale Guerra

University of Coimbra, Faculty of Psychology and Educational Sciences

Rua do Colégio Novo 3000-115 Coimbra joanaguerra@fpce.uc.pt

Dr. Catarina Leitão

University of Coimbra, Faculty of Psychology and Educational Sciences

Rua do Colégio Novo 3000-115 Coimbra

catarina.leitao@uc.pt 